\title{
Desempenho Produtivo de Novilhos Nelore, na Recria e na Engorda, Recebendo Dietas com Diferentes Níveis de Concentrado e Proteína ${ }^{1}$
}

\author{
Fabiano Ferreira da Silva², Sebastião de Campos Valadares Filho ${ }^{3}$, Luís Carlos Vinhas Ítavo ${ }^{4}$, Cristina Mattos \\ Veloso², Mário Fonseca Paulino ${ }^{3}$, Paulo Roberto Cecon ${ }^{5}$, Poliana Albino Silva ${ }^{6}$, Renan Marques Galvão ${ }^{6}$
}

\begin{abstract}
RESUMO - Foram utilizados 36 novilhos Nelore inteiros, com peso vivo médio inicial de $240 \mathrm{~kg}$, sendo quatro novilhos de referência e o restante distribuído em oito tratamentos, com quatro diferentes níveis de concentrado nas dietas (20, 40, 60 e $80 \%)$ e dois níveis de proteína bruta (PB) (15 e 18\%), expressos na MS. Avaliaram-se os consumos de matéria seca (MS), matéria orgânica (MO), PB, fibra em detergente neutro (FDN) e nutrientes digestíveis totais (NDT), os ganhos médios diários de peso vivo (GMD), de peso de corpo vazio (GMPVZ) e de carcaça (GC) e a conversão alimentar (CA). O consumo de MS não foi influenciado pelo nível de concentrado, na fase de recria, apresentando média de 7,06 kg/dia, porém, quando expresso em porcentagem do peso vivo (\% PV) e em gramas por unidade de tamanho metabólico ( $\left.\mathrm{g} / \mathrm{kg}^{0,75}\right)$, estimaram-se consumos máximos de 2,59\% PV e 107,32 g/ $\mathrm{kg}^{0,75}$, com 42,60 e 42,52\% de concentrado, respectivamente. Na fase de engorda, os níveis de concentrado não influenciaram o consumo de MS, observando-se valores médios de 7,16 kg/dia; $1,80 \%$ PV e $80,64 \mathrm{~g} / \mathrm{kg}^{0,75}$. O aumento do teor de proteína bruta da dieta, de 15 para $18 \%$, elevou o consumo de MS, na fase de recria, mas não influenciou o consumo na fase de engorda. Os níveis de concentrado das dietas não influenciaram os consumos de MO, PB e NDT, nas fases de recria e engorda, cujos valores médios, expressos em kg/dia, foram 6,50; 1,18; e 5,52, respectivamente, na recria; e 6,89; 1,20; e 5,59, respectivamente, na engorda. O consumo de FDN, expresso em kg/dia e \% PV, reduziu linearmente com o aumento do nível de concentrado. Os GMD, GMPCVZ, GC e CA não foram influenciados pelos níveis de concentrado da dieta, independentemente da fase estudada, cujas respectivas médias foram 1,$15 ; 1,13$ e $0,75 \mathrm{~kg} /$ dia e 6,29 , na recria, e 1,$05 ; 1,00$ e $0,71 \mathrm{~kg} /$ dia e 8,02 , na engorda. O teor de PB da dieta influenciou positivamente o GMD nas duas fases. A dieta com $18 \%$ de PB propiciou, aos novilhos, 22 e 22,6\% a mais de ganho de peso na recria e na engorda, respectivamente, comparada à dieta com $15 \%$ de PB. Os níveis mais altos de concentrado apresentaram os menores custo de produção por arroba, durante a fase de recria, e os níveis com 40 e $60 \%$ de concentrado apresentaram os menores custos por arroba, na engorda.
\end{abstract}

Palavras-chave: consumo, ganho de peso, Nelore, níveis de concentrado, níveis de proteína

\section{Productive Performance, during the Growing and Fattening Phases, of Nellore Bulls Fed Diets with Different Concentrate and Protein Levels}

\begin{abstract}
Thirty six Nellore bulls, with $240 \mathrm{~kg}$ initial live weight (LW), were used. Four were reference bulls and the remaining were distributed in eight treatments, with four different concentrate levels in the diets $(20 ; 40 ; 60$ and $80 \%)$ and two crude protein (CP) levels (15 and 18\%), in dry matter basis. The dry matter (DMI), organic matter (OM), CP, neutral detergent fiber (NDF) and total digestible nutrients (TDN) intakes were determined, as well as the average LW gain (LWG), empty body weight gain (EBWG), carcass gain (CG) and the feed conversion (FC). The DMI in the growing phase, expressed in $\mathrm{kg} / \mathrm{day}$, was not influenced by the concentrate level, presenting mean value of 7.06. But the DMI, expressed as a percentage of the LW (\% LW) and in grams for unit of metabolic size $(\mathrm{g} / \mathrm{kg} 0.75)$, in this phase, demonstrated a quadratic behavior in relation to the concentrate level, with maximum consumptions of $2.59 \% \mathrm{LW}$ and $107.32 \mathrm{~g} / \mathrm{kg}^{0.75}$, with 42.60 and $42.52 \%$ of concentrate, respectively. In the fattening phase, the concentrate levels did not influence the DMI, in any of the expressed ways, with mean values of $7.16 \mathrm{~kg} /$ day; $1.80 \% \mathrm{LW}$ and $80.64 \mathrm{~g} / \mathrm{kg}^{0.75}$. The increase in the diet CP level, from 15 to $18 \%$, caused a significant increase in the growing phase DMI, but it did not influence the consumption in the fattening phase. The diets concentrate levels did not influence the OM, CP and TND intakes, in the growing and fattening phases. The average values of OM, CP and TND intake, expressed in $\mathrm{kg}$ /day, were $6.50 ; 1.18$ and 5.52, respectively, during the growing phase; and $6.89 ; 1.20$ and 5.59, respectively, during the fattening phase. The NDF consumption, expressed in $\mathrm{kg} /$ day and in $\% \mathrm{LW}$, had a decreasing linear behavior with the concentrate level increase. LWG, EBWG, CG and FC were not influenced by the concentrate levels of the diet, independently of the studied phase. In the growing phase, the mean values for LWG, EBWG, CG and FC were $1.15 ; 1.13$ and $0.75 \mathrm{~kg}$ /day and 6.29 , respectively; and, in the fattening phase, they were $1.05 ; 1.00$ and $0.71 \mathrm{~kg}$ /day and 8.02 , respectively. The diet CP level had a positive influence on the LWG in both phases. The diet with $18 \%$ of CP provided, to the bulls, 22 and $22.6 \%$ more LWG in the growing and in the fattening phases, respectively, compared to the diet with $15 \% \mathrm{CP}$. The highest concentrate levels presented the smallest production cost during the growing phase, and the levels of 40 and $60 \%$ of concentrate presented the smallest cost in the fattening phase.
\end{abstract}

Key Words: concentrate levels, consumption, live weight gain, Nellore, protein levels

\footnotetext{
${ }^{1}$ Parte da tese de Doutorado em Zootecnia apresentada pelo primeiro autor à UFV. Financiada pela FAPEMIG.

2 Professor do curso de Zootecnia - UESB - Pç. Primavera, 40 - Itapetinga, BA. 45700-000. E.mail: ffsilva@uesb.br; cmveloso@uesb.br

3 Professor do Departamento de Zootecnia - UFV - Viçosa, MG. E.mail: svcfilho@ufv.br

4 Professor da Universidade Católica Dom Bosco - Campo Grande, MS. E.mail: itavo@ucdb.br

${ }^{5}$ Professor do Departamento de Informática - UFV - Viçosa, MG.

${ }^{6}$ Bolsista de Iniciação Científica/UFV - Viçosa, MG.
} 


\section{Introdução}

$\mathrm{Na}$ formulação de uma dieta completa para bovinos, deve-se considerar o fornecimento de níveis adequados de matéria seca (MS), energia, proteína bruta (PB), fibra em detergente neutro (FDN), fibra em detergente ácido (FDA), extrato etéreo (EE), além de minerais e vitaminas. A ingestão de MS é o fator mais importante na determinação do desempenho animal, pois é o ponto responsável pelo ingresso de nutrientes, principalmente energia e proteína, necessários ao atendimento das exigências de mantença e produção (Noller et al., 1999b). A habilidade de ganho de peso de bovinos é influenciada pelo nível nutricional ao qual são submetidos. Entretanto, a melhoria do nível nutricional proporciona aumento no custo da alimentação, o que, às vezes, pode tornar a atividade de baixa rentabilidade, principalmente quando os animais não possuem potencial para altos ganhos de peso. Assim, o consumo, a conversão alimentar e o ganho de peso são importantes parâmetros na avaliação dos animais.

O controle do consumo de alimentos, segundo Raymond (1969), citado por Forbes (1995), é explicado por duas teorias: a da distensão e a quimiostática. Já Mertens (1994) relatou que a ingestão de MS é controlada por fatores físicos, fisiológicos e psicogênicos. O mecanismo físico refere-se à distensão física do rúmen-retículo; o fisiológico é regulado pelo balanço energético ou nutricional; e a regulação psicogênica envolve o comportamento animal em resposta a fatores inibidores ou estimuladores no alimento ou no manejo alimentar, que não são relacionados ao valor energético do alimento, nem ao efeito de enchimento.

Como a fibra em detergente neutro (FDN), geralmente, fermenta e passa pelo rúmen-retículo mais lentamente que os outros constituintes nãofibrosos da dieta, ela tem maior efeito de enchimento que aqueles e se constitui no melhor preditor químico da ingestão voluntária de MS (Allen, 1996). Conforme sugerido por Mertens (1992), o consumo de FDN acima de 1,2\% do peso vivo regula o consumo por mecanismos físicos. Segundo Conrad et al. (1964), em dietas com digestibilidade inferior a $66 \%$, os fatores físicos determinam a ingestão de alimentos, enquanto, no caso de dietas com digestibilidade superior a este percentual, a ingestão de MS é controlada por fatores fisiológicos.

As informações, na literatura, em relação à me- lhor relação volumoso:concentrado para as dietas de bovinos de corte em crescimento não estão consolidadas. O estudo de como esta relação influi na cinética da digestão, bem como na utilização dos alimentos, é fundamental para a manipulação de dietas mais eficientes e de menor custo.

Dutra et al. (1997) ofereceram dietas com baixo ( $40 \%$ de FDN) ou alto teor de fibra (55\% de FDN) a novilhos taurinos e observaram aumentos aproximados de 30\% nos consumos de MS e matéria orgânica, quando expressos em porcentagem do peso vivo, quando se reduziu o teor de fibra da dieta.

Tibo et al. (2000), Oliveira et al. (1998) e Gesualdi Jr. et al. (2000), avaliando níveis crescentes de concentrado $(25 ; 37,5 ; 50 ; 62,5 ;$ e $75 \%)$ na dieta de zebuínos ou F1 europeu x zebu, em confinamento, encontraram resposta quadrática para consumo de $\mathrm{MS}$, expresso em \% $\mathrm{PV}$, sendo o maior valor alcançado com os níveis de $70 ; 58,5 ;$ e $36,7 \%$ de concentrado na dieta, respectivamente.

Ferreira et al. (1999), Ladeira et al. (1999) e Dias et al. (2000) relataram aumento linear de consumo, fornecendo rações com diferentes níveis de concentrado $(25 ; 37,5 ; 50 ; 62,5$; e $75 \%)$. Por outro lado, Carvalho et al. (1997) e Signoretti et al. (1999a) não verificaram diferenças no consumo de MS, ao fornecerem dietas com níveis crescentes de concentrado em substituição ao feno, e Bürger et al. (2000) verificaram diminuição linear do consumo de nutrientes com o aumento dos níveis de concentrado nas dietas $(30,45,60,75$ e 90\%). Isso mostra que maiores níveis de concentrado na dieta podem não levar ao resultado esperado.

Segundo Ferreira et al. (1999) e Oliveira et al. (1998), o ganho de peso médio diário apresenta resposta linear crescente em relação ao nível de inclusão de concentrado na dieta. Entretanto, segundo vários autores (Veira et al., 1994; Araújo et al., 1998; Tibo et al., 2000; Gesualdi Jr. et al., 2000), a resposta animal à adição de concentrado tende a ser quadrática e não-linear. Assim, o nível ótimo, considerando o desempenho animal e a eficiência econômica do sistema, é variável e tem como fatores determinantes sexo, raça do animal, qualidade dos alimentos, entre outros.

Outras características da dieta influenciam a regulação da ingestão de alimentos, entre elas a deficiência ruminal de compostos nitrogenados $(\mathrm{N})$, seja na forma de amônia, aminoácidos ou peptídeos. Quando o suprimento de N, originário do material 
ingerido ou da reciclagem endógena, não atende aos requisitos microbianos, ocorre limitação do crescimento microbiano (Sniffen et al., 1993) e depressão da digestão da parede celular (Wilson \& Kennedy, 1996), resultando em diminuição do consumo. Segundo Van Soest (1994), a depressão do consumo pode ser atribuída à deficiência de $\mathrm{N}$ para o animal, à redução na fermentação ruminal ou à menor saída de resíduos não-digeridos do rúmen.

A concentração e a qualidade da proteína da dieta podem alterar tanto o mecanismo físico como o quimiostático do consumo, nos ruminantes. A redução da proteína da dieta abaixo de $7 \%$ e a diminuição da disponibilidade de $\mathrm{N}$ podem reduzir a digestão da fibra e, subseqüentemente, restringir o consumo, em conseqüência da lenta passagem dos alimentos pelo rúmen. Por outro lado, níveis elevados de $\mathrm{N}$ podem induzir à toxidez, pelo excesso de liberação de amônia, reduzindo também o consumo. O NRC (1984) recomenda teores de $12 \%$ de PB para dietas de bovinos em terminação, mas Robinson et al. (1994), citados por NRC (1996), observaram aumentos significativos no balanço de $\mathrm{N}$ de novilhos que receberam dietas balanceadas para fornecer proteína em níveis acima das exigências do NRC (1984). Valadares et al. (1997) obtiveram maiores coeficientes de digestibilidade aparente da MS e da MO, quando a ração continha $14,5 \%$ de $\mathrm{PB}$, comparada com dietas que continham 7; 9,5; e $12 \%$ de PB.

Dessa forma, avaliou-se o desempenho de novilhos Nelore nas fases de recria, até $360 \mathrm{~kg}$, e terminação, até $450 \mathrm{~kg}$, recebendo dietas com quatro níveis de concentrado e dois níveis de $\mathrm{PB}$.

\section{Material e Métodos}

O experimento foi realizado no Departamento de Zootecnia da Universidade Federal de Viçosa, em Viçosa-MG. Foram utilizados 36 novilhos Nelore inteiros, com peso vivo médio inicial de $240 \mathrm{~kg}$ e 18 meses de idade, em média, confinados em baias individuais, com piso de concreto, providas de comedouro e bebedouro de concreto, com área total de $30 \mathrm{~m}^{2}$, sendo $8 \mathrm{~m}^{2}$ cobertos. Os animais passaram por um período de adaptação de 30 dias, durante o qual todos foram identificados, tratados contra ecto e endoparasitas e receberam a mesma dieta. Quatro novilhos foram abatidos após o período de adaptação (grupo referência), servindo de referência para estudos subseqüentes. Os 32 animais restantes foram pesados e distribuídos em oito tratamentos, com quatro diferentes níveis de concentrado nas dietas (20, 40, 60 e $80 \%$ ) e dois níveis de PB (15 e 18\%), na base da MS, em esquema fatorial $4 \times 2$ (níveis de concentrado $\mathrm{x}$ níveis de proteína) no delineamento inteiramente casualizado, com quatro repetições na fase de recria e duas repetições na fase de engorda. A fase de recria foi avaliada dos $240 \mathrm{~kg}$ aos $360 \mathrm{~kg}$ de peso vivo e a fase de engorda, dos $360 \mathrm{~kg}$ aos $450 \mathrm{~kg}$ de peso vivo.

$\mathrm{O}$ volumoso utilizado foi o feno de capim-Tifton (Cynodon dactylon). As rações foram formuladas de acordo com o NRC (1996). Todas as rações foram formuladas para conter próximo de $32 \%$ da PB na forma de compostos nitrogenados não-protéicos. As proporções dos ingredientes nos concentrados são apresentadas na Tabela 1; a composição bromatológica dos concentrados e do feno, na Tabela 2; e a composição bromatológica das dietas, na Tabela 3.

Os alimentos foram fornecidos à vontade, uma vez ao dia, e ajustados de forma a manter sobras em torno de 5 a $10 \%$ do fornecido, com água permanentemente à disposição dos animais. A quantidade de ração oferecida foi registrada diariamente e, semanalmente, foram coletadas amostras do feno e dos concentrados, por tratamento, e das sobras, por animal. As amostras semanais foram agrupadas, de forma proporcional, em cada período de 28 dias, constituindo-se em amostras compostas, as quais foram pré-secas em estufa ventilada a $65^{\circ} \mathrm{C}$ e processadas em moinho com peneira de malha de $1 \mathrm{~mm}$, para posteriores análises laboratoriais.

Foi realizada uma pesagem dos animais no início do experimento e, periodicamente, a cada 28 dias. À medida que um animal se aproximava do peso de abate preestabelecido, 360 ou $450 \mathrm{~kg}$ (recria e engorda, respectivamente), era pesado a intervalos menores. Antes do abate, os animais foram submetidos a um jejum de 16 horas. Após o abate, o trato gastrintestinal foi pesado, esvaziado e lavado. Após escorrimento da água de lavagem, o trato gastrintestinal, bem como todas as outras partes do corpo do animal, foi pesado para obtenção do peso de corpo vazio final. As carcaças foram pesadas após 18 horas de resfriamento a $-5^{\circ} \mathrm{C}$, para determinação do ganho de carcaça. Foi determinado o peso de corpo vazio inicial, bem como o peso de carcaça inicial, dos animais experimentais, a partir dos animais referência.

As determinações de matéria seca (MS), matéria orgânica (MO), nitrogênio total, extrato etéreo (EE), fibra em detergente neutro (FDN) e macroelementos 
Tabela 1 - Proporção dos ingredientes nos concentrados, na base da matéria natural

Table 1 - Proportion of ingredients used in the concentrates, as fed basis

\begin{tabular}{|c|c|c|c|c|c|c|c|c|}
\hline \multirow{2}{*}{$\begin{array}{l}\text { Nível de concentrado (\%) } \\
\text { Concentrate level } \\
\text { Teor de PB } \\
\text { CP content }\end{array}$} & \multicolumn{2}{|c|}{20} & \multicolumn{2}{|c|}{40} & \multicolumn{2}{|c|}{60} & \multicolumn{2}{|c|}{80} \\
\hline & 15 & 18 & 15 & 18 & 15 & 18 & 15 & 18 \\
\hline $\begin{array}{l}\text { Fubá de milho }(\%) \\
\text { Wheat middling }\end{array}$ & 88,72 & 59,74 & 91,96 & 77,10 & 93,05 & 83,20 & 95,37 & 86,16 \\
\hline $\begin{array}{l}\text { Farelo de soja }(\%) \\
\text { Soybean meal }\end{array}$ & 4,75 & 32,44 & 4,38 & 18,35 & 4,03 & 13,50 & 1,76 & 11,01 \\
\hline $\begin{array}{l}\text { Uréia }(\%) \\
\text { Urea }\end{array}$ & 2,93 & 4,65 & 1,58 & 2,43 & 1,16 & 1,70 & 1,25 & 1,35 \\
\hline $\begin{array}{l}\text { Calcário calcítico (\%) } \\
\text { Limestone }\end{array}$ & 0,045 & 0,02 & 0,54 & 0,79 & 0,88 & 0,87 & 1,04 & 1,04 \\
\hline $\begin{array}{l}\text { Fosfato bicálcico (\%) } \\
\text { Dicalcium phosphate }\end{array}$ & 2,78 & 2,42 & 1,12 & 0,94 & 0,57 & 0,45 & 0,33 & 0,20 \\
\hline & 0,70 & 0,65 & 0,38 & 0,36 & 0,28 & 0,26 & 0,23 & 0,21 \\
\hline $\begin{array}{l}\text { Premix mineral }(\mathrm{g} / 100 \mathrm{~kg})^{1} \\
\text { Mineral mix }\end{array}$ & 84,04 & 84,04 & 42,02 & 42,02 & 28,00 & 28,00 & 21,00 & 21,00 \\
\hline
\end{tabular}

${ }^{1}$ Composição (Composition): sulfato de zinco (zinc sulfate), 80,00\%; sulfato de cobre (cupper sulfate), 19,00\%; iodato de potássio (potassium iodate), $0,50 \%$; sulfato de cobalto (cobalt sulfate), $0,25 \%$; selenito de sódio (sodium selenite), $0,25 \%$.

Tabela 2 - Teores médios de matéria seca (MS), matéria orgânica (MO), proteína bruta (PB), extrato etéreo (EE), fibra em detergente neutro (FDN), carboidratos não-estruturais $(\mathrm{CNE})$, cálcio $(\mathrm{Ca})$ e fósforo $(\mathrm{P})$ dos concentrados e do feno

Table 2 - Average contents of dry matter (DM), organic matter (OM), crude protein (CP), ether extract (EE), neutral detergent fiber (NDF), non structural carbohydrates (NEC), calcium (C) and phosphorus $(P)$ of the concentrates and hay

\begin{tabular}{|c|c|c|c|c|c|c|c|c|c|}
\hline \multirow{2}{*}{$\begin{array}{l}\text { Nível de concentrado (\%) } \\
\text { Concentrate level } \\
\text { Teor de PB } \\
\text { CP content }\end{array}$} & \multicolumn{2}{|c|}{20} & \multicolumn{2}{|c|}{40} & \multicolumn{2}{|c|}{60} & \multicolumn{2}{|c|}{80} & \multirow[b]{2}{*}{$\begin{array}{c}\text { Feno } \\
\text { Hay }\end{array}$} \\
\hline & 15 & 18 & 15 & 18 & 15 & 18 & 15 & 18 & \\
\hline $\mathrm{MS}(D M), \%$ & 87,30 & 87,19 & 87,29 & 87,41 & 87,33 & 87,45 & 88,55 & 86,85 & 88,55 \\
\hline $\mathrm{MO}(M O)^{1}$ & 95,77 & 94,08 & 96,37 & 96,00 & 97,02 & 96,43 & 96,55 & 96,79 & 94,18 \\
\hline $\mathrm{PB}(C P)^{1}$ & 21,98 & 37,87 & 16,62 & 22,93 & 15,78 & 21,03 & 14,63 & 17,86 & 14,09 \\
\hline $\mathrm{EE}^{1}$ & 2,78 & 1,53 & 4,30 & 1,13 & 2,66 & 2,10 & 1,89 & 1,87 & 1,93 \\
\hline FDN $(N D F)^{1,2}$ & 14,01 & 5,16 & 9,86 & 4,45 & 13,53 & 8,05 & 13,81 & 5,94 & 74,47 \\
\hline $\mathrm{CNE}(N E C)^{1}$ & 57,00 & 49,52 & 65,59 & 67,49 & 65,05 & 62,25 & 66,22 & 71,12 & 3,69 \\
\hline $\mathrm{Ca}^{1}$ & 0,96 & 1,01 & 0,70 & 0,79 & 0,71 & 0,63 & 0,84 & 0,75 & 0,36 \\
\hline $\mathrm{P}^{1}$ & 0,95 & 1,01 & 0,48 & 0,64 & 0,40 & 0,46 & 0,50 & 0,38 & 0,20 \\
\hline
\end{tabular}

$1 \%$ na matéria seca (\% in dry matter).

${ }^{2}$ FDN corrigida para cinzas e proteína (NDF corrected for ash and protein).

minerais $(\mathrm{Ca}, \mathrm{P})$ foram realizadas conforme técnicas descritas por Silva (1990), sendo que a proteína bruta (PB) foi obtida pelo produto entre o teor de nitrogênio total e o fator 6,25 . A solução mineral para determinação dos macroelementos minerais foi preparada por via úmida. Após as devidas diluições, o teor de $\mathrm{P}$ foi determinado por colorimetria e o de $\mathrm{Ca}$, em espectrofotômetro de absorção atômica. Os carboidratos não-fibrosos (CNF) foram obtidos pela relação $100-(\% \mathrm{~PB}+\% \mathrm{EE}+\% \mathrm{MM}+\mathrm{FDN})$, conforme recomendações de Sniffen et al. (1992).
Os valores de NDT das dietas foram obtidos por ensaio de digestibilidade, de acordo com Ítavo (2001), que utilizaram os mesmos animais e dietas.

Os resultados foram interpretados, estatisticamente, por meio de análises de variância e regressão, utilizando-se o Sistema de Análises Estatísticas e Genéticas - SAEG (UFV, 1995). Os critérios utilizados para escolha do modelo foram o coeficiente de determinação $\left(\mathrm{r}^{2} / \mathrm{R}^{2}\right.$, em \%) ajustado, que foi calculado como a relação entre a soma de quadrado da regressão e a soma de quadrado de tratamento, e a 
Tabela 3 - Teores médios de matéria seca (MS), matéria orgânica (MO), proteína bruta (PB), extrato etéreo (EE), fibra em detergente neutro (FDN), carboidratos não-fibrosos (CNF), nutrientes digestíveis totais (NDT), cálcio (Ca) e fósforo (P) das dietas experimentais

Table 3 - Average contents of dry matter (DM), organic matter (OM), crude protein (CP), ether extract (EE), neutral detergent fiber (NDF), non fiber carbohydrates (NFC), total digestible nutrients (TDN), calcium (C) and phosphorus (P) of the experimental diets

\begin{tabular}{|c|c|c|c|c|c|c|c|c|}
\hline \multirow{2}{*}{$\begin{array}{l}\text { Nível de concentrado }(\%) \\
\text { Concentrate level } \\
\text { Teor de PB } \\
\text { CP content }\end{array}$} & \multicolumn{2}{|c|}{20} & \multicolumn{2}{|c|}{40} & \multicolumn{2}{|c|}{60} & \multicolumn{2}{|c|}{80} \\
\hline & 15 & 18 & 15 & 18 & 15 & 18 & 15 & 18 \\
\hline $\mathrm{MS}(D M), \%$ & 88,21 & 88,28 & 88,05 & 88,09 & 87,79 & 87,92 & 87,58 & 87,67 \\
\hline $\mathrm{MO}(M O)^{1}$ & 94,50 & 94,16 & 95,06 & 94,91 & 95,88 & 95,53 & 96,08 & 96,27 \\
\hline $\mathrm{PB}(C P)^{1}$ & 15,67 & 18,85 & 15,10 & 17,63 & 15,11 & 18,26 & 14,52 & 17,11 \\
\hline $\mathrm{EE}^{1}$ & 2,30 & 2,05 & 3,03 & 1,76 & 2,46 & 2,13 & 1,95 & 1,93 \\
\hline FDN $(N D F)^{1}$ & 62,37 & 60,60 & 48,62 & 46,46 & 37,90 & 34,62 & 25,94 & 19,65 \\
\hline CNF $(N F C)^{1}$ & 14,16 & 12,66 & 28,31 & 29,06 & 40,41 & 40,52 & 53,67 & 57,58 \\
\hline NDT $(T D N)^{1}$ & 73,80 & 73,16 & 77,73 & 79,33 & 79,61 & 81,46 & 81,94 & 78,39 \\
\hline $\mathrm{Ca}^{1}$ & 0,48 & 0,49 & 0,50 & 0,53 & 0,57 & 0,52 & 0,74 & 0,67 \\
\hline $\mathrm{P}^{1}$ & 0,35 & 0,37 & 0,31 & 0,39 & 0,32 & 0,36 & 0,44 & 0,34 \\
\hline
\end{tabular}

$1 \%$ na matéria seca (\% in dry matter).

${ }^{2}$ FDN corrigida para cinzas e proteína (NDF corrected for ash and protein).

significância observada entre tratamentos por meio do teste $\mathrm{F}$, em níveis de 1 ou $5 \%$ de probabilidade. Os coeficientes de regressão foram comparados pelo teste "t" a 1 e $5 \%$ de probabilidade.

\section{Resultados e Discussão}

As análises de variância não evidenciaram a existência de interação de níveis de concentrado com teor de proteína bruta $(\mathrm{P}>0,01)$, para qualquer variável estudada. Estão apresentadas na Tabela 4 as médias e regressões ajustadas dos consumos diários de matéria seca (MS), proteína bruta (PB), fibra em detergente neutro (FDN) e nutrientes digestíveis totais (NDT), por nível de concentrado (NC) e por porcentagem de $\mathrm{PB}$ na dieta, na fase de recria. $\mathrm{Na}$ Tabela 5, estão apresentadas as mesmas variáveis, para a fase de engorda.

O consumo de MS, expresso em $\mathrm{kg} / \mathrm{dia}$, não foi influenciado $(\mathrm{P}>0,01)$ pelo nível de concentrado, na fase de recria, apresentando média de 7,06. O consumo de MS, quando foi expresso em porcentagem do peso vivo (\% PV) e em gramas por unidade de tamanho metabólico $\left(\mathrm{g} / \mathrm{kg}^{0,75}\right)$, nesta fase, demonstrou comportamento quadrático em relação ao nível de concentrado, com consumos máximos estimados de 2,59\% $\mathrm{PV}$ e $107,32 \mathrm{~g} / \mathrm{kg}^{0,75}$, com 42,60 e $42,52 \%$ de concentrado, respectivamente. $\mathrm{Na}$ fase de engorda, os níveis de concentrado não influenciaram o consumo de MS, observando-se valores médios de 7,16 kg/dia, 1,80\% PV e $80,64 \mathrm{~g} / \mathrm{kg}^{0,75}$.

R. Bras. Zootec., v.31, n.1, p.492-502, 2002 (Suplemento)
Os animais, na terminação, apresentaram menores valores numéricos de consumo, quando expresso em \% PV e em g/kg0,75. A composição corporal, especialmente a porcentagem de gordura corporal, parece afetar a ingestão de alimentos. À medida que o animal se aproxima da maturidade, mais gordura é depositada. Em geral, quanto mais gordo o animal, menor o consumo de alimentos, para qualquer tamanho corporal. Um dos motivos é a redução na capacidade abdominal de acomodar o trato digestivo, com aumento do volume da gordura abdominal (Forbes, 1993). Outra causa seria o efeito de "feedback" do tecido adiposo no controle do consumo. O consumo/ unidade de peso metabólico começa a declinar por volta de $350 \mathrm{~kg}$ de peso, para um novilho de porte médio (NRC, 1987). Isto pode ser visualizado na Figura 1, com os dados deste experimento, que demonstraram efeito linear decrescente do PV sobre o consumo de MS.

Avaliações de desempenho de bovinos na recria, em confinamento, são escassas. Ladeira et al. (1999) observaram respostas lineares e positivas no consumo de MS, em relação aos níveis de concentrado, em todas as formas expressas, para novilhos Nelore com peso vivo médio de $244,6 \mathrm{~kg}$. Os resultados de consumo de MS em relação aos níveis de concentrado na dieta são variáveis, dependendo da raça e da dieta fornecida, entre outros fatores. Avaliações do consumo de MS em resposta a diferentes níveis de concentrado, durante o período de engorda, expresso em \% PV, já revelaram respostas positivas lineares (Ferreira et 
Tabela 4 - Médias, coeficientes de variação (CV, \%) e equações de regressão ajustadas dos consumos diários de matéria seca (MS), matéria orgânica (MO), proteína bruta (PB), fibra em detergente neutro (FDN) e nutrientes digestíveis totais (NDT), em função do nível de concentrado (NC) e teor de PB na dieta, na fase de recria, e os respectivos coeficientes de determinação $\left(r^{2} / R^{2}\right)$

Table 4 - Means, coefficients of variation (CV, \%) and fitted regression equations of daily intakes of dry matter (DM), organic matter (OM), crude protein (CP), neutral detergent fiber (NDF) and total digestible nutrients (TDN), on the concentrate level (CL) and CP content in the diet, in the growing phase, and the respective coefficients of determination $\left(r^{2} / R^{2}\right)$

\begin{tabular}{|c|c|c|c|c|c|c|c|}
\hline \multirow[t]{2}{*}{$\begin{array}{l}\text { Consumos } \\
\text { Intakes }\end{array}$} & \multicolumn{4}{|c|}{$\begin{array}{l}\text { Nível de concentrado (\%) } \\
\text { Concentratelevel }\end{array}$} & \multicolumn{2}{|c|}{$\begin{array}{l}\text { Teor de } \mathrm{PB} \\
\text { CP content }\end{array}$} & \multirow[t]{2}{*}{$\mathrm{CV}(\%)$} \\
\hline & 20 & 40 & 60 & 80 & 15 & 18 & \\
\hline $\begin{array}{l}\mathrm{MS}, \mathrm{kg} / \mathrm{dia} \\
D M, \mathrm{~kg} / \text { day }\end{array}$ & 7,06 & 7,81 & 7,14 & 6,25 & $6,70^{b}$ & $7,43^{\mathrm{a}}$ & 15,40 \\
\hline $\begin{array}{l}\mathrm{MS}^{1}, \% \mathrm{PV} \\
D M^{1}, \% L W\end{array}$ & 2,39 & 2,64 & 2,43 & 2,11 & $2,29^{b}$ & $2,50^{\mathrm{a}}$ & 11,10 \\
\hline $\begin{array}{l}\mathrm{MS}^{2}, \mathrm{~g} / \mathrm{kg}^{0,75} \\
D M^{2}, \mathrm{~g} / \mathrm{kg}^{75}\end{array}$ & 99,09 & 109,44 & 100,60 & 87,33 & $94,48^{b}$ & $103,75^{\mathrm{a}}$ & 11,52 \\
\hline $\begin{array}{l}\mathrm{MO}, \mathrm{kg} / \mathrm{dia} \\
M O, \mathrm{~kg} / \mathrm{day}\end{array}$ & 6,45 & 7,13 & 6,68 & 5,74 & $6,31^{\mathrm{a}}$ & $6,69^{\mathrm{a}}$ & 16,57 \\
\hline $\begin{array}{l}\mathrm{PB}, \mathrm{kg} / \mathrm{dia} \\
\mathrm{CP}, \mathrm{kg} / \text { day }\end{array}$ & 1,24 & 1,30 & 1,17 & 1,00 & $1,02^{\mathrm{b}}$ & $1,33^{\mathrm{a}}$ & 14,02 \\
\hline $\begin{array}{l}\mathrm{FDN}^{3}, \mathrm{~kg} / \mathrm{dia} \\
N D F^{3}, \mathrm{~kg} / \text { day }\end{array}$ & 4,53 & 3,97 & 2,62 & 1,58 & $3,03^{\mathrm{a}}$ & $3,32^{\mathrm{a}}$ & 16,88 \\
\hline $\begin{array}{l}\mathrm{FDN}^{4}, \% \mathrm{PV} \\
N D F^{4}, \% L W\end{array}$ & 1,54 & 1,35 & 0,89 & 0,53 & $1,03^{\mathrm{b}}$ & $1,12^{\mathrm{a}}$ & 11,61 \\
\hline $\begin{array}{l}\mathrm{NDT}, \mathrm{kg} / \mathrm{dia} \\
T D N, \mathrm{~kg} / \text { day }\end{array}$ & 5,19 & 6,13 & 5,76 & 5,00 & $5,23^{\mathrm{a}}$ & $5,80^{\mathrm{a}}$ & 15,37 \\
\hline
\end{tabular}

Médias seguidas de pelo menos uma mesma letra na linha, para os teores de PB, não diferem a $1 \%$ de probabilidade pelo teste $\mathrm{F}$.

** Significativo a $1 \%$ de probabilidade pelo teste t.

Means followed by the same letter in a row, for the CP contents, do not differ at $1 \%$ of probability by $F$ test).

${ }^{* *}$ Significant at $1 \%$ of probability by $t$ test).

${ }^{1} \hat{Y}=1,93966+0,0306771^{* *} N C-0,000360165^{* *} N C^{2} R^{2}=0,96$

${ }^{2} \hat{Y}=80,6239+1,25563^{\star \star} N C-0,014763^{\star \star} N C^{2} R^{2}=0,96$.

${ }^{3} \hat{Y}=5,73162-0,0511097^{* *} N C R^{2}=0,83$.

${ }^{4} \hat{Y}=1,94551-0,0173389^{* *} N C R^{2}=0,88$.

al., 1999; Dias et al., 2000 e Tibo et al., 2000); respostas quadráticas, de acordo com Gesualdi Jr. et al. (2000), que estimaram consumo máximo de $1,99 \% \mathrm{PV}$, com $36,71 \%$ de concentrado; e ausência de qualquer resposta, como observado neste experimento, semelhante ao encontrado por Véras (2000), que obteve valor médio de consumo de $2,14 \% \mathrm{PV}$, para novilhos Nelore.

$\mathrm{Na}$ engorda, mesmo com $20 \%$ de concentrado, o consumo não foi limitado fisicamente, sendo respaldado pelo bom valor de NDT desta dieta $(>73 \%$, Tabela 3). Segundo Conrad et al. (1964), em dietas com digestibilidade maior que $66 \%$, o consumo de MS é controlado por fatores fisiológicos, o que provavelmente ocorreu neste estudo.

$\mathrm{O}$ aumento do teor de proteína bruta da dieta, de 15 para $18 \%$, elevou o consumo de MS $(\mathrm{P}<0,01)$, na fase de recria, mas não influenciou o consumo na fase de engorda.

Os níveis de concentrado das dietas não influenci-

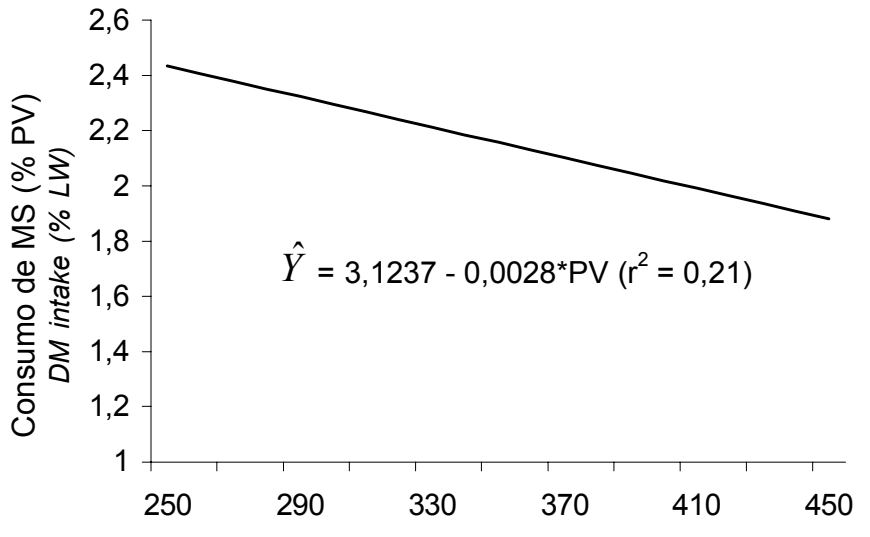

Peso vivo $(\mathrm{kg})$

Live weight $(\mathrm{kg})$

Figura 1 - Estimativa do consumo de matéria seca (MS), expresso em \% PV, em função do peso vivo do animal, em $\mathrm{kg}$.

Figure 1 - Estimate of dry matter (DM) intake, in \%LW, in function of animal live weight $(\mathrm{kg})$. 
aram $(\mathrm{P}>0,01)$ os consumos de $\mathrm{MO}, \mathrm{PB}$ e NDT, nas fases de recria e engorda. Os valores médios de consumo de MO, PB e NDT, expressos em kg/dia, foram 6,50; 1,18 ; e 5,52, respectivamente, durante a fase de recria; e 6,$89 ; 1,20$; e 5,59, respectivamente, durante a fase de engorda. Normalmente, o consumo destes nutrientes reflete o mesmo comportamento verificado para a ingestão de MS, em kg/dia. Araújo et al. (1998) e Véras (2000) observaram respostas quadráticas para o consumo dos nutrientes e Ferreira et al. (1999), respostas lineares, em função dos níveis de concentrado, à semelhança do consumo de MS.

Como esperado, o consumo de PB foi maior nas dietas com maior teor de PB (18\%), tanto na recria $(1,020 \mathrm{~kg} \times 1,330 \mathrm{~kg})$ quanto na engorda $(1,030 \mathrm{~kg} \mathrm{x}$ $1,370 \mathrm{~kg}$ ), conforme pode ser observado nas Tabelas 4 e 5 .

O consumo de FDN, expresso em $\mathrm{kg} /$ dia e \% PV, apresentou comportamento linear decrescente com o aumento do nível de concentrado, devido à redução da proporção de volumoso da dieta, ingrediente que contém altos teores de fibra. Como a FDN geralmente fermenta e passa pelo rúmen-retículo mais lentamente que os outros constituintes não-fibrosos da dieta, tem maior efeito de enchimento que aqueles e constitui-se no melhor preditor químico da ingestão voluntária de MS (Allen, 1996). Neste experimento, os teores de FDN da dieta não influenciaram $(\mathrm{P}>0,01)$ o consumo de MS na fase de engorda.

Conforme sugerido por Mertens (1992), o consumo de FDN acima de $1,2 \%$ do peso vivo regula o consumo por mecanismos físicos. $\mathrm{Na}$ fase de recria, o consumo de FDN capaz de regular o consumo de MS por mecanismos físicos parece estar em um nível acima da recomendação de Mertens (1992), talvez acima de $1,35 \% \mathrm{PV}$. Isto demonstra que o limite físico do rúmen é elástico e torna-se maior, à medida que o déficit no atendimento da exigência metabólica se torna maior. Biologicamente, é provável que o déficit cause, simultaneamente, diminuição da produção e aumento da limitação física (Waldo, 1986). Na fase de engorda, os animais sempre ingeriram menos de $1,2 \%$ PV de FDN.

$\mathrm{Na}$ Tabela 6, estão apresentadas as médias para os ganhos médios diários de peso vivo (GMD) e de

Tabela 5 - Médias, coeficientes de variação (CV, \%) e equações de regressão ajustadas dos consumos diários de matéria seca (MS), matéria orgânica (MO), proteína bruta (PB), fibra em detergente neutro (FDN) e nutrientes digestíveis totais (NDT), em função do nível de concentrado (NC) e teor de PB na dieta, na fase de engorda, e os respectivos coeficientes de determinação $\left(r^{2} / R^{2}\right)$

Table 5 - Means, coefficients of variation (CV, \%) and fitted regression equations of daily intakes of dry matter (DM), organic matter (OM), crude protein (CP), neutral detergent fiber (NDF) and total digestible nutrients (TDN), on the concentrate level (CL) and CP content in the diet, in the fattening phase, and the respective coefficients of determination $\left(r^{2} / R^{2}\right)$

\begin{tabular}{|c|c|c|c|c|c|c|c|}
\hline \multirow[t]{2}{*}{$\begin{array}{l}\text { Consumos } \\
\text { Intakes }\end{array}$} & \multicolumn{4}{|c|}{$\begin{array}{l}\text { Nível de concentrado (\%) } \\
\text { Concentrate level }\end{array}$} & \multicolumn{2}{|c|}{$\begin{array}{l}\text { Teor de } \mathrm{PB} \\
C P \text { content }\end{array}$} & \multirow[t]{2}{*}{$\mathrm{CV}(\%)$} \\
\hline & 20 & 40 & 60 & 80 & 15 & 18 & \\
\hline $\begin{array}{l}\mathrm{MS}, \mathrm{kg} / \mathrm{dia} \\
D M, \mathrm{~kg} / \text { day }\end{array}$ & 7,48 & 7,38 & 7,23 & 6,54 & $6,75^{\mathrm{a}}$ & $7,56^{\mathrm{a}}$ & 14,19 \\
\hline $\begin{array}{l}\mathrm{MS}, \% \mathrm{PV} \\
D M, \% L W\end{array}$ & 1,88 & 1,87 & 1,83 & 1,66 & $1,71^{\mathrm{a}}$ & $1,91^{\mathrm{a}}$ & 11,63 \\
\hline $\begin{array}{l}\mathrm{MS}, \mathrm{g} / \mathrm{kg}^{0,75} \\
D M, \mathrm{~g} / \mathrm{kg}^{.75}\end{array}$ & 83,83 & 83,36 & 81,54 & 73,84 & $76,19^{a}$ & $85,10^{\mathrm{a}}$ & 12,27 \\
\hline $\begin{array}{l}\mathrm{MO}, \mathrm{kg} / \mathrm{dia} \\
D M, \mathrm{~kg} / \text { day }\end{array}$ & 7,19 & 7,09 & 6,95 & 6,28 & $6,49^{\mathrm{a}}$ & $7,27^{\mathrm{a}}$ & 14,16 \\
\hline $\begin{array}{l}\mathrm{PB}, \mathrm{kg} / \mathrm{dia} \\
C P, \mathrm{~kg} / \text { day }\end{array}$ & 1,32 & 1,22 & 1,21 & 1,04 & $1,03^{\mathrm{b}}$ & $1,37^{\mathrm{a}}$ & 12,25 \\
\hline $\begin{array}{l}\mathrm{FDN} 1, \mathrm{~kg} / \mathrm{dia} \\
N D F 1, \mathrm{~kg} / \mathrm{day}\end{array}$ & 4,79 & 3,72 & 2,77 & 1,68 & $3,03^{\mathrm{a}}$ & $3,45^{\mathrm{a}}$ & 13,95 \\
\hline $\begin{array}{l}\mathrm{FDN} 2, \% \mathrm{PV} \\
N D F 2, \% L W\end{array}$ & 1,20 & 0,94 & 0,70 & 0,43 & $0,77^{\mathrm{a}}$ & $0,87^{\mathrm{a}}$ & 11,52 \\
\hline $\begin{array}{l}\text { NDT, } \mathrm{kg} / \mathrm{dia} \\
T D N, \mathrm{~kg} / \text { day }\end{array}$ & 5,49 & 5,79 & 5,82 & 5,24 & $5,29^{\mathrm{a}}$ & $5,89^{\mathrm{a}}$ & 14,33 \\
\hline
\end{tabular}

Médias seguidas de pelo menos uma mesma letra na linha, para os teores de $\mathrm{PB}$, não diferem a $1 \%$ de probabilidade pelo teste $\mathrm{F}$

** Significativo a $1 \%$ de probabilidade pelo teste $\mathrm{t}$.

Means followed by the same letter, in a row, for the CP contents, do not differ at $1 \%$ of probability by $F$ test.

${ }^{* *}$ Significant at $1 \%$ of probability by $t$ test.

${ }^{1} \hat{\mathrm{Y}}=5,80906-0,0513541^{* *} \mathrm{NC} \mathrm{r}^{2}=0,93$

$2 \hat{\mathrm{Y}}=1,45981-0,0128324^{* *} \mathrm{NC} \mathrm{r}^{2}=0,94$

R. Bras. Zootec., v.31, n.1, p.492-502, 2002 (Suplemento) 
peso de corpo vazio (GMDPVZ), o ganho diário de carcaça (GC) e a conversão alimentar (CA), por nível de concentrado e de proteína bruta da dieta. Nenhuma destas variáveis foram influenciadas ( $\mathrm{P}>0,01)$ pelos níveis de concentrado da dieta, independentemente da fase estudada. Na recria, as médias de GMD, GMDPVZ, GC e CA foram 1,15, 1,13 e $0,75 \mathrm{~kg} / \mathrm{dia}$ e 6,29 , respectivamente; e na engorda foram $1,05,1,00$ e $0,71 \mathrm{~kg} /$ dia e 8,02 , respectivamente. Os resultados da literatura demonstram respostas lineares para GMD, GMDPCVZ e GC (Oliveira, 1998; Resende, 1999; Ferreira et al., 1999); ou quadráticas (Gesualdi Jr. et al., 2000) para o GMD e $\mathrm{GC}$, em relação à inclusão de concentrado na dieta. Com relação à conversão alimentar, os resultados sempre demonstraram resposta linear decrescente em resposta à inclusão de concentrado na dieta (Oliveira, 1998; Resende, 1999; Ferreira et al., 1999; Gesualdi Jr. et al., 2000), diferentemente do encontrado neste experimento. A possível explicação para estes fatos seria, talvez, o bom valor nutritivo do feno utilizado neste experimento, que propiciou às dietas, mesmo aquelas com apenas $20 \%$ de concentrado, digestibilidade da MS acima de 75\% (Ítavo, 2001).
Com isso, nenhuma dieta limitou fisicamente o consumo a ponto de limitar o desempenho. Contribuindo com estes resultados, o potencial genético dos animais utilizados neste experimento, talvez, fosse baixo, não permitindo que os ganhos fossem maiores com o aumento do valor energético da dieta, sendo já atingidos na dieta de menor valor energético $(20 \%$ de concentrado).

$\mathrm{O}$ teor de $\mathrm{PB}$ da dieta influenciou positivamente $(\mathrm{P}<0,01)$ o ganho médio diário de peso vivo nas duas fases. A dieta com $18 \%$ de PB propiciou, aos novilhos, 22,11 e $22,58 \%$ a mais de ganho de peso na recria e na engorda, respectivamente, comparada à dieta com 15\% de PB (Tabela 6). O NRC (1996) recomenda, para novilhos de $250 \mathrm{~kg}$ de $\mathrm{PV}$, ganhando 1,2 kg de PV/dia, o consumo de $930 \mathrm{~g}$ de $\mathrm{PB}$ e, para novilhos de $400 \mathrm{~kg}$ de PV, ganhando 1,0 kg de PV/dia, o consumo de $956 \mathrm{~g}$ de $\mathrm{PB}$, assumindo uma eficiência de utilização da PB de 64\%. Utilizando os valores médios de consumo de MS deste experimento, os requisitos de $\mathrm{PB}$, para as fases de recria e engorda, seriam de 13,3 e $11,8 \%$. Pode-se notar que houve respostas no desempenho, quando foram oferecidas quantidades de proteína bem acima das recomenda-

Tabela 6 - Médias e coeficientes de variação (CV, \%) para ganhos médios diários de peso vivo (GMD) e de peso de corpo vazio (GMDPVZ), ganho de carcaça (GCAR) e conversão alimentar (CA), em função do nível de concentrado e teor de PB na dieta, nas fases de recria e de engorda

Table 6 - Means and coefficients of variation (CV, \%), for average daily live weight gain (ADLWG) and empty body weight (ADEBW), carcass gain (CARG) and feed:gain ratio (F/G) on the concentrate level $(C L)$ and $C P$ content in the diet, in the growing and fattening phases

\begin{tabular}{|c|c|c|c|c|c|c|c|}
\hline \multirow[t]{2}{*}{$\begin{array}{l}\text { Consumos } \\
\text { Intakes }\end{array}$} & \multicolumn{4}{|c|}{$\begin{array}{c}\text { Nível de concentrado }(\%) \\
\text { Concentrate level }\end{array}$} & \multicolumn{2}{|c|}{$\begin{array}{c}\text { Teor de PB } \\
C P \text { content }\end{array}$} & \multirow[t]{2}{*}{$\mathrm{CV}(\%)$} \\
\hline & 20 & 40 & 60 & 80 & 15 & 18 & \\
\hline \multicolumn{8}{|c|}{ Recria (Growing) } \\
\hline $\begin{array}{l}\mathrm{GMD}, \mathrm{kg} / \mathrm{dia} \\
A D L W G, \mathrm{~kg} / \text { day }\end{array}$ & 1,12 & 1,27 & 1,09 & 1,15 & $1,04^{b}$ & $1,27^{\mathrm{a}}$ & 22,73 \\
\hline $\begin{array}{l}\text { GMDPVZ, kg/dia } \\
A D E B W, \mathrm{~kg} / \text { day }\end{array}$ & 0,92 & 1,30 & 1,17 & 1,14 & $1,04^{\mathrm{a}}$ & $1,22^{\mathrm{a}}$ & 23,63 \\
\hline $\begin{array}{l}\mathrm{GCAR}, \mathrm{kg} / \mathrm{dia} \\
C A R G, \mathrm{~kg} / \text { day }\end{array}$ & 0,63 & 0,84 & 0,78 & 0,76 & $0,69^{\mathrm{a}}$ & $0,81^{\mathrm{a}}$ & 26,60 \\
\hline $\begin{array}{l}\mathrm{CA} \\
F / G \\
\end{array}$ & 6,52 & 6,35 & 6,86 & 5,44 & $6,65^{\mathrm{a}}$ & $5,97^{\mathrm{a}}$ & 16,62 \\
\hline \multicolumn{8}{|c|}{ Engorda (Fattening) } \\
\hline $\begin{array}{l}\mathrm{GMD}, \mathrm{kg} / \mathrm{dia} \\
A D L W G, \mathrm{~kg} / \text { day }\end{array}$ & 1,07 & 0,99 & 1,02 & 1,05 & $0,93^{\mathrm{b}}$ & $1,14^{\mathrm{a}}$ & 16,57 \\
\hline $\begin{array}{l}\text { GMDPVZ, kg/dia } \\
A D E B W, \mathrm{~kg} / \text { day }\end{array}$ & 0,98 & 1,04 & 1,03 & 0,97 & $0,92^{\mathrm{a}}$ & $1,09^{\mathrm{a}}$ & 28,14 \\
\hline $\begin{array}{l}\mathrm{GCAR}, \mathrm{kg} / \mathrm{dia} \\
C A R G, \mathrm{~kg} / \text { day }\end{array}$ & 0,65 & 0,74 & 0,73 & 0,72 & $0,70^{\mathrm{a}}$ & $0,72^{\mathrm{a}}$ & 32,84 \\
\hline $\begin{array}{l}\text { CA } \\
F / G\end{array}$ & 7,04 & 7,56 & 7,58 & 9,91 & $7,52^{\mathrm{a}}$ & $8,52^{\mathrm{a}}$ & 51,15 \\
\hline
\end{tabular}

Médias seguidas de pelo menos uma mesma letra, na linha, para os teores de PB, não diferem a $1 \%$ de probabilidade pelo teste $\mathrm{F}$.

Means followed by the same letter, in a row, for the CP contents, do not differ at $1 \%$ of probability by $F$ test. 
ções do NRC (1996). Fica a necessidade de se estudar melhor, nos bovinos, a nutrição protéica, tanto em relação à quantidade quanto à qualidade.

Na Tabela 7, são apresentados os custos de produção, por nível de concentrado e de PB na dieta, durante as fases de recria e de engorda. Os custos com alimentação representaram 82,6 e $80,8 \%$ do custo total, nas fases de recria e engorda, respectivamente. Observa-se que os níveis mais altos de concentrado apresentaram os menores custo de

Tabela 7 - Custo de produção por nível de concentrado e de proteína bruta na dieta durante as fases de recria e engorda Table 7 - Production cost by concentrate level and crude protein in the diet, in the growing and fattening phases

Nível de concentrado (\%)

Concentratelevel

Custo de produção $(\mathrm{R} \$)^{1}$

20

$20 \quad 40$

60

80

Teor de PB

$C P$ content

Production cost

Produção em arrobas

Recria (Growing)

Productionin@

Custo de alimentação ${ }^{2}$

4,20

5,12

5,26

5,54

4,77

5,29

Feeding cost $t^{2}$

Custo com vermifugações

135,54

159,01

135,13

161,74

153,56

161,62

Medicaments cost

2,08

2,08

2,08

2,08

2,08

Custo da mão-de-obra ${ }^{3}$

14,73

13,94

16,66

16,39

16,68

14,18

Depreciações ${ }^{4}$

12,86

12,86

12,86

12,86

12,86

12,86

Depreciation $^{4}$

2,48

2,82

2,50

2,90

2,78

2,86

Capital remuneration 5

Estimativa do custo total

167,69

190,71

169,24

145,97

187,95

193,60

Total cost estimate

Estimativa custo/arroba

42,07

37,57

32,34

34,90

39,30

37,48

Estimatecost/@

Produção em arrobas

Productionin@

Custo de alimentação ${ }^{2}$

Feeding cost ${ }^{2}$

Custo com vermifugações

Medicaments cost

Custo da mão-de-obra ${ }^{3}$

Labor cost $t^{3}$

Depreciações 4

Depreciation $^{4}$

Remuneração do capital ${ }^{5}$

Capital remuneration ${ }^{5}$

Estimativa do custo total

Total cost estimate

Estimativa custo/arroba

Estimatecost/@

Engorda (Fattening)

\begin{tabular}{|c|c|c|c|c|c|}
\hline \multicolumn{4}{|c|}{ Engorda (Fattening) } & \multirow[b]{2}{*}{3,59} & \multirow[b]{2}{*}{3,14} \\
\hline 3,01 & 3,34 & 3,48 & 3,60 & & \\
\hline 111,49 & 106,28 & 114,00 & 122,89 & 110,70 & 116,22 \\
\hline 2,08 & 2,08 & 2,08 & 2,08 & 2,08 & 2,08 \\
\hline 9,83 & 9,38 & 9,48 & 10,83 & 10,43 & 9,45 \\
\hline 12,86 & 12,86 & 12,86 & 12,86 & 12,86 & 12,86 \\
\hline 2,04 & 1,96 & 2,08 & 2,23 & 2,04 & 2,11 \\
\hline 138,31 & 132,57 & 140,49 & 150,89 & 138,11 & 142,72 \\
\hline 46,01 & 39,72 & 41,42 & 51,76 & 39,13 & 50,04 \\
\hline
\end{tabular}

1 Cotação do dólar em julho/2000 = R \$ 1,81.

2 Considerando: Preço do feno de capim-coastcross $=\mathrm{R} \$ 0,16 / \mathrm{kg}$ de matéria natural.

Preço do concentrado $=\mathrm{R} \$ 0,197 ; \mathrm{R} \$ 0,201 ; \mathrm{R} \$ 0,205$ e $\mathrm{R} \$ 0,215$, para os níveis de $80,60,40$ e $20 \%$ de concentrado na dieta com $15 \%$ de proteína bruta; e $\mathrm{R} \$ 0,209 ; \mathrm{R} \$ 0,214 ; \mathrm{R} \$ 0,224$ e $\mathrm{R} \$ 0,253$, para os níveis de $80,60,40$ e $20 \%$ de concentrado na dieta com $18 \%$ de proteína bruta.

3 Considerando: Um homem ( $R \$ 206,37 /$ mês = salário mínimo + encargos sociais $+13^{\circ}$ salário + férias $) / 30$ dias $/ 50$ animais $=R \$ 0,138 / a n i m a l / d i a$.

4 Considerando: Custo do curral de confinamento $=R \$ 5.000,00$ e vida útil de 10 anos; custo do galpão de feno $=R \$ 10.000,00$ e vida útil de 15 anos; custo da picadeira de feno $=R \$ 3.000,00$ e vida útil de 10 anos; e custo da balança para pesagem de gado para $1500 \mathrm{~kg}=\mathrm{R} \$ 2.100,00$ e vida útil de 10 anos.

5 Considerando-se uma taxa de juros de 6\%/ano.

1 U $\$ 1.00$ in July/2000 $=R \$ 1,81$.

2 Considering coastcross hay price: $R \$ 0.16 / \mathrm{kg}$ as fed. Concentrate price $=R \$ 0.197 ; R \$ 0.201 ; R \$ 0.205$ and $R \$ 0.215$, for levels of $80,60,40$ and $20 \%$ of concentrate in the diet with $15 \%$ crude protein; and $R \$ 0.209 ; R \$ 0.214 ; R \$ 0.224$ and $R \$ 0.253$, for levels of $80,60,40$ and $20 \%$ of concentrate in the diet with $18 \%$ crude protein. Considering income tax of $6 \% / y e a r$.

\section{R. Bras. Zootec., v.31, n.1, p.492-502, 2002 (Suplemento)}


produção por arroba, durante a fase de recria. Signoretti et al. (1999b), abatendo novilhos holandeses aos 190 ou $300 \mathrm{~kg}$ de peso vivo, obtiveram os menores custos por arroba nos tratamentos com 90 e $75 \%$ de concentrado, respectivamente. Na dieta com $18 \%$ de PB, embora o custo total de produção tenha sido maior, o custo por arroba foi menor que o da dieta com $15 \%$ de $\mathrm{PB}$, pois o maior nível de $\mathrm{PB}$ elevou a produção de arrobas, na fase de recria.

$\mathrm{Na}$ fase de engorda, o teor mais alto de PB (18\%) produziu uma arroba mais cara $(\mathrm{R} \$ 50,04)$ que a dieta com $15 \%$ de $\mathrm{PB}$ ( R \$39,13), devido ao maior custo da suplementação protéica e à maior conversão alimentar nesta fase. Os níveis com 40 e $60 \%$ de concentrado apresentaram os menores custos por arroba.

\section{Conclusões}

Os teores de $\mathrm{PB}$ das dietas de animais zebu foram maiores que os recomendados pelo NRC (1996).

Possivelmente o melhor nível de concentrado na dieta de zebu esteja próximo de $40 \%$.

\section{Literatura Citada}

ALLEN, M.S. Physical constraints on voluntary intake of forages by ruminants. Journal Animal Science, v.74, n.12, p.30633075, 1996.

ARAÚJO, G.G.L.; SILVA., J.F.C.; VALADARES FILHO, S.C. et al. Ganho de peso, conversão alimentar e características da carcaça de bezerros alimentados com dietas contendo diferentes níveis de volumoso. Revista Brasileira de Zootecnia, v.27, n.5, p.1006-1012, 1998.

BÜRGUER, P.J.; PEREIRA, J.C.; SILVA., J.F.C. et al. Consumo e digestibilidade aparente total e parcial em bezerros Holandeses alimentados com dietas contendo diferentes níveis de concentrado. Revista Brasileira de Zootecnia, v.29, n.1, p.206-214, 2000.

CARVALHO, A.U.; VALADARES FILHO, S.C.; SILVA, J.F.C. et al. Níveis de concentrado em dietas de zebuínos. 1. Consumo e digestibilidade aparente. Revista Brasileira de Zootecnia, v.26, n.5, p.986-995, 1997.

CONRAD, H.R.; PRATT, A.D.; HIBBS, J.W. Regulation of feed intake in dairy cows. 1. Change in importance of physical and physiological factors with increasing digestibility. Journal Dairy Science, v.47, p.54-, 1964.

DIAS, H.L.C.; VALADARES FILHO, S.C.; SILVA, J.F.C. et al. Consumo e digestões totais e parciais em novilhos F1 Limousin $\mathrm{x}$ Nelore alimentados com dietas contendo cinco níveis de concentrado. Revista Brasileira de Zootecnia, v.29, n.2, p.545-554, 2000.

DUTRA, A.R.; QUEIROZ, A.C.; PEREIRA, J.C. et al. Efeitos dos níveis de fibra e das fontes de proteínas sobre o consumo e digestão dos nutrientes em novilhos. Revista Brasileira de Zootecnia, v.26, n.4, p.787-796, 1997.

FERREIRA, M.A.; VALADARES FILHO, S.C.; SILVA, J.F.C. et al. Consumo, conversão alimentar, ganho de peso e carac- terísticas da carcaça de bovinos F1 Simental x Nelore. Revista Brasileira de Zootecnia, v.28, n.2, p.343-351, 1999.

FORBES, J.M. Voluntary feed intake. In: FORBES, J.M.; FRANCE, J. (Eds.) Quantitative aspects of ruminant digestion and metabolism. Cambridge: $\mathrm{CAB}$ International, 1993. p.479-494.

FORBES, J.M. Voluntary food intake and diet selection in farm animals. Guiford: Biddles, 1995. 532p.

GESUALDI JR., A., PAULINO, M.F., VALADARES FILHO, S.C. et al. Níveis de concentrado na dieta de novilhos F1 Limousin $\mathrm{x}$ Nelore: consumo, conversão alimentar e ganho de peso. Revista Brasileira de Zootecnia, v.29, n.5, p.1458-1466, 2000.

ÍTAVO, L.C.V. Consumo, digestibilidade e eficiência microbiana de novilhos alimentados com 20, 40, 60 e $80 \%$ de concentrado. Viçosa, MG: Universidade Federal de Viçosa. Tese (Doutorado em Zootecnia) - Universidade Federal de Viçosa, 2001.

LADEIRA, M.M.; VALADARES FILHO, S.C.; SILVA, J.F.C. et al. Consumo e digestibilidades aparentes totais e parciais de dietas contendo diferentes níveis de concentrado, em novilhos Nelore. Revista Brasileira de Zootecnia, v.28, n.2, p.395-403, 1999.

MERTENS, D.R. Análise da fibra e sua utilização na avaliação de alimentos e formulação de rações. In: SIMPÓSIO INTERNACIONAL DE RUMINANTES, 1992, Lavras. Anais... Lavras: Sociedade Brasileira de Zootecnia, 1992. p.188-219.

MERTENS, D.R. Regulation of forage intake. In: FAHEY Jr., G.C. (Ed.) Forage quality, evaluation and utilization. Madison: American Society of Agronomy, 1994. p.450-493.

NATIONAL RESEARCH COUNCIL - NRC. Nutrient requirements of beef cattle. 7.ed. Washington, D.C.: National Academy Press, 1996. 242p.

NATIONAL RESEARCH COUNCIL - NRC. Nutrient requirements of beef cattle. 6.ed. Washington, D.C.: National Academy Press, 1984. 90p.

NATIONAL RESEARCH COUNCIL - NRC. Predicting feed intake of food-producing animals. Washington, D.C.: National Academy Press, 1987. 85p.

NOLLER, C.H.; NASCIMENTO Jr., D.; QUEIROZ, D.S. Exigências nutricionais de animais em pastejo. In: PEIXOTO, A.M.; MOURA, J.C.; FARIA, V.P. (Eds.) SIMPÓSIO SOBRE MANEJO DA PASTAGEM, 13., 1996, Piracicaba. Produção de bovinos a pasto. Anais... Piracicaba: Fundação de Estudos Agropecuários “Luiz de Queiroz”, 1997. p.319-352.

OLIVEIRA. S.R. Desempenho e características da carcaça de novilhos Nelores não-castrados. Viçosa, MG: Universidade Federal de Viçosa, 1998. 58p. Dissertação (Mestrado em Zootecnia) - Universidade Federal de Viçosa, 1998.

RESENDE, F.D. Avaliação de diferentes proporções de volumoso:concentrado sobre a ingestão, digestibilidade, ganho de peso e conversão alimentar de bovinos mestiços confinados. Viçosa, MG: Universidade Federal de Viçosa, 1999. 78p. Tese (Doutorado em Zootecnia) - Universidade Federal de Viçosa, 1999.

SIGNORETTI, R.D.; SILVA, J.F.C.; VALADARES FILHO, S.C. et al. Consumo e digestibilidade aparente em bezerros da raça Holandesa alimentados com dietas contendo diferentes níveis de volumoso. Revista Brasileira de Zootecnia, v.28, n.1, p.169-177.

SIGNORETTI, R.D.; SILVA, J.F.C.; VALADARES FILHO, S.C. et al. Crescimento, conversão alimentar e rendimento de 
carcaça de bezerros da raça Holandesa alimentados com dietas contendo diferentes níveis de volumoso. Revista Brasileira de Zootecnia, v.28, n.1, p.185-194, 1999b.

SILVA, D.J. Análise de alimentos (métodos químicos e biológicos). Viçosa, MG: Universidade Federal de Viçosa, 1990. 165p.

SNIFFEN, C.J.; BEVERLY, R.W.; MOONEY, C.S. et al. Nutrient requirement versus supply in dairy cow: Strategies to account for variability. Journal Dairy Science, v.76, n.10, p.31603178, 1993.

SNIFFEN, C.J.; O'CONNOR, J.D.; VAN SOEST, P.J. et al. A net carbohydrate and protein system for evaluating cattle diets: II. Carbohydrate and protein availability. Journal Animal Science, v.70, p.3562-3577, 1992.

TIBO, G.C.; VALADARES FILHO, S.C.; VALADARES, R.F.D. et al. Níveis de concentrado em dieta de novilhos mestiços F1 Simental x Nelore: consumo e digestibilidades. Revista Brasileira de Zootecnia, v.29, n.3, p.910-920, 2000.

UNIVERSIDADE FEDERAL DE VIÇOSA - UFV. SAEG Sistema de análises estatísticas e genética. Viçosa, $\mathrm{MG}$, 1995. (Apostila).

VALADARES, R.F.D.; GONÇALVES, L.C.; RODRÍGUEZ, N.M. et al. Níveis de proteína em dietas de bovinos. 1. Consumo e digestibilidade aparente totais e parciais. Revista Brasileira de Zootecnia, v.26, n.6, p.1252-1258, 1997.

Van SOEST, P.J. Nutritional ecology of the ruminant. 2.ed. Ithaca: Cornell University Press, 1994. 476p.
VEIRA, D.M.; BUTLER, G.; PROULX, J.G. et al. Utilization of grass silage by cattle: effect of suplementation with different sources and amounts of protein. Journal Animal Science, v.72, n.6, p.1403-1408, 1994.

VÉRAS, A.S.C. Consumo, digestibilidade, composição corporal e exigências nutricionais de bovinos Nelore alimentados com rações contendo diferentes níveis de concentrado. Viçosa, MG: Universidade Federal de Viçosa, 2000. 192p. Tese (Doutorado em Zootecnia) - Universidade Federal de Viçosa, 2000.

WALDO, D.R. Effect of forage quality on intake and forageconcentrate interactions. Journal Dairy Science, v.69, n.2, p.617-631, 1986.

WILSON, J.R.; KENNEDY, P.M. Plant and animal contraits to voluntary feed intake associated with fibre characteristics and particle breakdown and passage in ruminants. Australian Journal of Agriculture Research, v.47, n.1, p.199-225, 1996.

Recebido em: 29/04/01

Aceito em: 29/11/01 